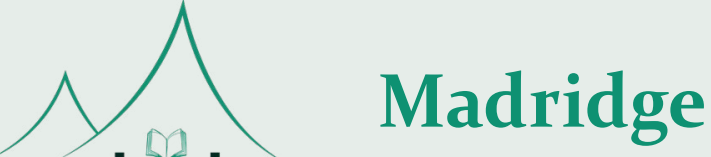 \\ madridge Journal of Nursing \\ nterconnecting Scientific World
}

Research Article

Open Access

\section{Prevent Hypertension, a Modifiable Life Style Disease by IEC activity}

\author{
Urmila Bhardwaj $^{1 *}$, Poonam Sharma ${ }^{2}$, and Anju Hooda ${ }^{3}$ \\ ${ }^{1}$ Associate Professor, Hamdard University, Jamia Hamdard, New Delhi, India \\ ${ }^{2}$ Msc student, Rufaida college of Nursing, Jamia Hamdard, New Delhi, India \\ ${ }^{3}$ Tutor, Jamia Hamdard, New Delhi, India
}

Article Info

*Corresponding author:
Urmila Bhardwaj
Associate Professor
Hamdard University
India
E-mail: urmila_48@rediffmail.com

Received: March 7, 2017

Accepted: August 8, 2017

Published: August 14, 2017

Citation: Bhardwaj U, Sharma P, Hooda A. Prevent Hypertension, A Modifiable Life Style Disease by IEC activity. Madridge J Nurs. 2017; 2(1): 44-47.

doi: $10.18689 / \mathrm{mjn}-1000108$

Copyright: ( $\odot 2017$ The Author(s). This work is licensed under a Creative Commons Attribution 4.0 International License, which permits unrestricted use, distribution, and reproduction in any medium, provided the original work is properly cited.

Published by Madridge Publishers

\begin{abstract}
The quantitative (experimental) one group pre-test post-test study was done to identify the effectiveness of IEC Programme in terms ofknowledge and practice of modifiable risk factors for prevention of hypertension among women in age group 18-40 years in selected area of Delhi. The main objective of this study was to evaluate the effectiveness of IEC Programme in increasing the knowledge and practice on modifiable risk factors for prevention of hypertension among women. Results: IEC Programme had made significant improvement in the knowledge and practice among women. Thus, it is concluded that the IEC programme was effective in enhancing the knowledge and practice of the women regarding modifiable risk factors for prevention of hypertension.
\end{abstract}

Keywords: Knowledge; Practice; IEC; Hypertension; Modifiable risk factors.

\section{Introduction}

Hypertension is a global, non-communicable chronic disease and is largely asymptomatic. Hypertension in which the blood pressure in the arteries is elevated, requiring the heart to work harder than normal to circulate blood through the blood vessels. It has been described as the "silent killer" because initially the disease presents no apparent symptoms, and hence an individual can have hypertension without realizing it. A person experiences very few signs and symptoms until damage occurs to a target organ [1].

The World Health Organization (WHO) attributes hypertension, or high blood pressure, as the leading cause of cardiovascular mortality. The World health league (WHL), as umbrella organization of 85 national hypertension societies and leagues, recognized that more than $50 \%$ of the hypertensive population worldwide are unaware of their condition. To address this problem, the WHL Initiated a global awareness campaign on hypertension in 2005 and dedicated May 17 of each year as World Hypertension Day (WHD) [2].

Information Education and communication (IEC) is a process that inform, motivates helps people to adopt and maintain healthy practices and life skills. It aims at empowering individuals and enabling them to make correct decisions about safe behaviour practices. The education programme is the best instrument in the prevention of occurrence of Hypertension by helping people to take care of their own health. Although community education is the best instrument to impart knowledge, providing information is not the only solution. The education must include strategies for motivation also [3]. 
WHO recognizes the importance of reducing the level of exposure of individuals and populations to the common modifiable risk factors for non-communicable diseases including hypertension and strengthening the capacity to make healthier choices and follow lifestyle patterns that foster good health. Exposure to these risk factors begins in childhood and continued in adulthood, so the health promoting interventions should be initiated as early as possible to prevent modifiable risk factors [4].

The effectiveness of health education as an intervention study is evident from its basic objective that is to influence the behaviour (life style) that may affect both health and illness), including behaviours necessary to prevent illness and promote health, as well as those necessary to enhance recovery and to help persons live with disabilities or chronic dysfunctions (e.g., hypertension) throughout their lives $[5,6]$.

It was identified that there is lack of knowledge and practice of women regarding the modifiable risk factors of hypertension and felt that educating the women will help in prevention of hypertension. Educational interventions can be effectively targeted and implemented as prevention strategies to reduce the burden of disease.

\section{Main Body/Methods}

The aim of the study was to evaluate the effectiveness of Information Education and Communication (IEC) intervention in increasing the knowledge and practice on modifiable risk factors for prevention of hypertension among women of age 18-40 years in selected area of Delhi. The study was a quantitative (experimental) research approach with one group pre-test post-test design. Systematic Random Sampling Technique was used for selecting women. Knowledge and practice questionnaire was used for collecting data.On the Day 1, the pre-test for knowledge and practice related to modifiable risk factors of hypertension for all women was administered. IEC was administered on Day 2. IEC included information about meaning of hypertension, aetiology, nonmodifiable risk factors, modifiable risk factors such as diet, obesity, smoking, stress and physical inactivity and measures to prevent them, symptoms and control of hypertension. The investigatorgave proper guideline to them. At the end of teaching, the women were asked to clarify any doubt and copy of pamphlets on modifiable risk factors and its preventionwere given to each women at the end of session. On Day 9 ( $7^{\text {th }}$ day after IEC), the post-test for knowledge and practice identical to pre-test was administered in order to evaluate the effectiveness of IEC intervention. The data were collected, organized, tabulated and analysed using descriptive and inferential statistics. ' $z$ ' test statistical method was used to analyze the data.

The data were entered in a master data sheet followed by the analysis and interpretation based on data collected through structured questionnaire. The data was analyzed and presented under the following sections.

\section{Section I. Demographic characteristics}

Maximum of the subjects (45\%) were in the age group of 26-35 years, most of the study participants (57.5\%) were Hindu. Maximum of the study subjects were educated up to Senior Secondary level (52.5\%). The family income of $50 \%$ of the study subjects was more than Rs. 20,000 . About $70 \%$ of the women were residing in Nuclear family and about $35 \%$ women gave family history of heart disease (Presented in table 1).

Table 1. Frequency and Percentage Distribution of study subjects by their demographic characteristics.

$\mathrm{n}=40$

\begin{tabular}{|l|l|c|c|}
\hline \multicolumn{2}{|c|}{ Demographic Characteristics } & $\begin{array}{c}\text { Frequency } \\
\text { (n) }\end{array}$ & $\begin{array}{c}\text { Percentage } \\
\text { (\%) }\end{array}$ \\
\hline 1. Age (in years) & $18-25$ & 12 & 30 \\
& $26-35$ & 18 & 45 \\
2. Religion & $36-40$ & 10 & 25 \\
\hline & Hindu & 23 & 57.5 \\
& Muslim & 13 & 32.5 \\
& Christian & 2 & 5.0 \\
& Sikh & 2 & 5.0 \\
\hline 3. Educational Qualification & Secondary & 10 & 25.0 \\
& education & 21 & 52.5 \\
& Senior Secondary & 9 & 22.5 \\
& Graduate & & \\
\hline 4. Family Income (in & $<10,000$ & 4 & 10 \\
Rupees) & $10,000-15,000$ & 6 & 15 \\
& $15,001-20,000$ & 10 & 25 \\
& $>20,000$ & 20 & 50 \\
\hline 5. Type of Family & Nuclear & 28 & 70 \\
& Joint & 12 & 30 \\
\hline 6. Family Member with & Yes & 14 & 35 \\
history of Heart Disease & No & 26 & 65 \\
\hline
\end{tabular}

\section{Section II. Findings related to evaluation} ofEffectiveness of IEC programme developed in terms of knowledge of study subjects

In pre test, majority $26(65 \%)$ had poor knowledge. After administering the IEC, 10 women $25 \%$ showed improvement in knowledge thereby scoring above average whereas $27(67.5 \%)$ scored average score. The mean post-test knowledge scoreof 31.00 regarding modifiable risk factors for prevention of hypertension was higher than their mean pre-test knowledge score 16.00 with mean difference of 15.00 . This indicates that there is gain in knowledge by all study subjects. The computed ' $Z$ ' value 17.21 is greater than the standard ' $Z$ ' value of 1.96. This indicated that IEC programme developed on modifiable risk factors for prevention of hypertension was effective in increasing the knowledge of women (Presented in table 2, 3 and Figure 1).

Table 2. Frequency and Percentage Distribution of study subjects on the basis of their knowledge

$\mathrm{n}=40$

\begin{tabular}{|c|c|c|c|c|}
\hline \multirow{2}{*}{$\begin{array}{c}\text { Level of } \\
\text { knowledge }\end{array}$} & \multicolumn{2}{|c|}{ Pre-test } & \multicolumn{2}{c|}{ Post Test } \\
\cline { 2 - 5 } & $\begin{array}{c}\text { Frequency } \\
\text { (n) }\end{array}$ & $\begin{array}{c}\text { Percentage } \\
(\%)\end{array}$ & $\begin{array}{c}\text { Frequency } \\
(\mathbf{n})\end{array}$ & $\begin{array}{c}\text { Percentage } \\
(\%)\end{array}$ \\
\hline Good & 4 & 10 & 10 & 25 \\
\hline Average & 10 & 25 & 27 & 67.5 \\
\hline Poor & 26 & 65 & 3 & 7.5 \\
\hline
\end{tabular}


Table 3. Mean, Median, Mean differences, standard deviation and ' $Z$ ' value of pre-test and post-test knowledge scores of study subjects $\mathrm{n}=40$

\begin{tabular}{|c|c|c|c|c|c|}
\hline $\begin{array}{c}\text { Knowledge } \\
\text { test }\end{array}$ & Mean & Median & $\begin{array}{c}\text { Standard } \\
\text { deviation }\end{array}$ & $\begin{array}{c}\text { Mean } \\
\text { difference }\end{array}$ & Z value \\
\hline Pre-test & 16.00 & 12.00 & 9.82 & 15.00 & $17.21^{*}$ \\
\hline Post-test & 31.00 & 30.00 & 9.76 & & \\
\hline
\end{tabular}

\section{$Z(38)=(2.02) 1.96, p<0.05 .{ }^{*}$ Significant at 0.05 level}

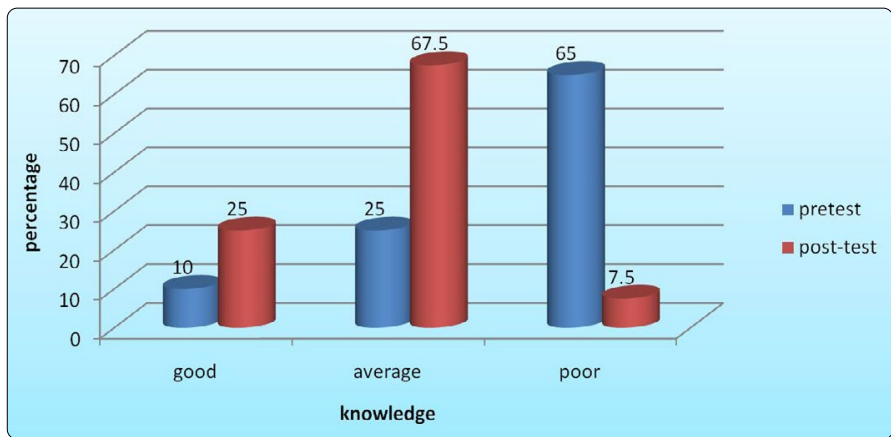

Figure 1. Bar diagram showing the percentage Level of knowledge of women in pre-test and post-test in structured knowledge questionnaire

\section{Section III: Findings related to evaluation of effectiveness of IEC programme developed in terms of practice of study subjects}

In pre-test majority 25 (62.5\%) had average and $10 \%$ had poor practice. After administering the IEC 16 women 40\% showed improvement in practice thereby scoring good whereas $16(40 \%)$ scored average score.The computed ' $Z$ ' value 10.33 is greater than the standard ' $Z$ ' value of 1.96 . This shows that the difference obtained in the mean pre-test and post-test practice scores was true difference and not by chance. This indicated that IEC programme developed on modifiable risk factors for prevention of hypertension was effective in improving the practice of women. (Presented in table 4, 5 and Figure. 2).

Table 4. Frequency and Percentage Distribution of study subjects on the basis of their practice

$\mathrm{n}=40$

\begin{tabular}{|c|c|c|c|c|}
\hline \multirow{2}{*}{$\begin{array}{c}\text { Level of } \\
\text { practice }\end{array}$} & \multicolumn{2}{|c|}{ Pre-test } & \multicolumn{2}{c|}{ Post Test } \\
\cline { 2 - 5 } & $\begin{array}{c}\text { Frequency } \\
(\mathrm{n})\end{array}$ & $\begin{array}{c}\text { Percentage } \\
(\%)\end{array}$ & $\begin{array}{c}\text { Frequency } \\
(\mathrm{n})\end{array}$ & $\begin{array}{c}\text { Percentage } \\
(\%)\end{array}$ \\
\hline Good & 4 & 10 & 16 & 40 \\
\hline Average & 25 & 62.5 & 16 & 40 \\
\hline Poor & 11 & 27.5 & 8 & 20 \\
\hline
\end{tabular}

Table 5. Mean, Median, Mean differences, standard deviation and ' $Z$ ' value of pre-test and post- test practice scores $n=40$

\begin{tabular}{|c|c|c|c|c|c|}
\hline Practice test & Mean & Median & $\begin{array}{c}\text { Standard } \\
\text { deviation }\end{array}$ & $\begin{array}{c}\text { Mean } \\
\text { difference }\end{array}$ & Z value \\
\hline Pre-test & 50.45 & 52.00 & 25.92 & 16.90 & $10.33^{*}$ \\
\hline Post-test & 73.35 & 71.50 & 20.33 & & \\
\hline
\end{tabular}

$Z(38)=(2.02) 1.96, p<0.05$. ${ }^{*}$ Significant at 0.05 level

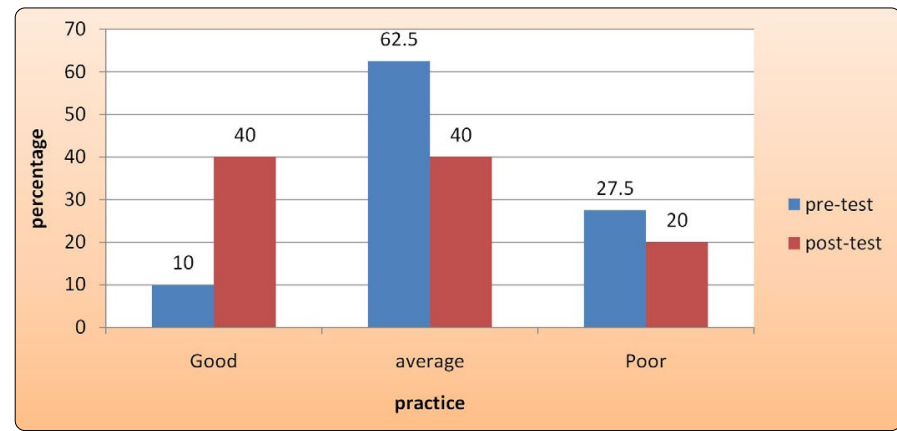

Figure 2. Bar diagram showing the percentage Level of practice of women in pre-test and post-test in structured practice questionnaire.

\section{Section IV: Findings related to relationship between post-test knowledge and practice scores of study subjects}

The calculated value of coefficient of correlation $(r)$ is 0.731 which is higher than the table value i.e. 0.304 at $\mathrm{df}$ (38). This indicates that there is significant positive relationship between post-test knowledge and post-test practice scores at 0.05 level of significance (presented in table 6).

Table 6. Coefficient of correlation between post-test knowledge scores and post-test practice scores on modifiable risk factors for prevention of hypertension

$\mathrm{n}=40$

\begin{tabular}{|c|c|c|c|c|c|}
\hline \multirow{2}{*}{ Test } & \multicolumn{2}{|c|}{ Knowledge scores } & \multicolumn{2}{c|}{ Practice scores } & \multirow{2}{*}{ ' ${ }^{\prime}$} \\
\cline { 2 - 5 } & Mean & SD & Mean & SD & \\
\hline Post test & 31.00 & 9.76 & 73.35 & 20.33 & $0.731^{\text {* }}$ \\
\hline
\end{tabular}

$r(38)=(0.304), P<0.001$, *significant at 0.05 level of significance

The limitations of present study were small Sample size that is(40 women) which limits the generalization of findings. Due to time limit for data collection, repeated administration of IEC could not be attempted in identifying areas of deficit in knowledge and practice of women.

The study recommendations are the study can be replicated on larger sample, a similar study can be conducted in a different community, a comparative study can be conducted between rural and urban areas to compare their knowledge and practice on modifiable risk factors for prevention of hypertension, longitudinal study can be conducted to find out the efficacy/long term effect of IEC on practice for prevention of hypertension, the comparative study can be carried out on effectiveness of IEC with other strategies e.g. Information booklet etc.

\section{Conclusion}

The women participated in this study were very much interested in learning new topic. The ' $z$ ' test was computed between mean pre-test knowledge scores and mean post-test knowledge scores indicate significant gain in knowledge among women. Thus it is concluded that IEC programme developed on modifiable risk factors for prevention of 
hypertension was effective in increasing the knowledge of women. The ' $z$ ' test was computed between mean pre-test practice scores and mean post-test practice scores indicate significant gain in practice among women. Thus it is concluded that IEC programme developed on modifiable risk factors for prevention of hypertension was effective in increasing the practice of women.

The present study revealed that initially the women had a low level of knowledge and practice skill but after IEC intervention the score were significantly higher than pre-test. There was a positive correlation between post-test knowledge and practice scores. The IEC programme was found to be an effective strategy in increasing the knowledge and practice of women. On the basis of the present study it may be concluded that the IEC is useful for enhancing the knowledge and practice in population.

\section{Limitations}

- Small sample size (40) which limits the generalizations of findings.

- Time limit for data collection due to which repeated administration of IEC could not be performed in areas of deficit knowledge and practice of women.

\section{Conflict of interest}

The authors confirm that there is no conflict of interest regarding this manuscript.

\section{References}

1. Park K, Park's Textbook of Preventive and Social Medicine. $21^{\text {st }}$ edition. 2011.

2. WHO, Non communicable disease in south East Asian region Geneva. 2011.

3. Kishore J, National Health Programs of India, 11 th edition, 2014.

4. WHO, Global action plan for the prevention and control of noncommunicable diseases-2013-2020. 2013.

5. Kaur S, Devi A. Right K, Panchal R. A Study to Evaluate the Effectiveness of Health Education Programme on Management of Hypertension for Hypertensive Clients in Terms of Knowledge, Compliance and Life Style in Khan Ahmedpur Village of District Ambala, Haryana. Int. J. Sci. Res. 2015; 4(2): 1258-69.

6. Mahajan H, Kaur YK, Sharma B, Velhal GD. Education: an Effective Intervention in Hypertensive Patients. Int. J. Recent. Sci. Tech. 2012; 4(2): 77-82 